\title{
Inmunohistoquímica y arquitectura genómica en el cáncer pulmonar: perspectiva desde la cirugía de tórax
}

\author{
Immunohistochemistry and genomic architecture in \\ lung cancer: a perspective from chest surgery
}

\author{
Álvaro Casallas Gómez, MD. FACS ${ }^{1}$
}

\section{Resumen}

El cáncer pulmonar en los Estados Unidos para el año 2020 representó la segunda causa de cáncer y la primera causa de mortalidad por cáncer. En 2016 se reportaron 538.000 casos de cáncer pulmonar con 80.775 hombres y 68.096 mujeres fallecidas en el mismo año. La sobrevida a cinco años referida en el año 2011 de 15.6 \% se elevó a 19.4 \% en 2019, probablemente asociada a disminución de personas fumadoras y, en especial, por avances en terapias farmacológicas focalizadas y al desarrollo de inmunoterapias.

$\mathrm{El}$ adenocarcinoma pulmonar particularmente en mujeres jóvenes y no fumadoras ha evidenciado incidencia aumentada. No obstante, la sobrevida en esta población ha tenido avances significativos asociados a un mejor conocimiento actual de mecanismos biológicos y genéticos identificables en el cáncer pulmonar y a una mejor clasificación de estos tumores en tipos y subtipos.

Numerosos avances en técnicas de inmunohistoquímica (en el diagnóstico y clasificación del cáncer del pulmón y selección de casos para análisis molecular) y el conocimiento de alteraciones genómicas asociadas a varios tipos de cáncer pulmonar, han cambiado su enfoque de tratamiento, en especial en estadios avanzados de la tumorogénesis. Oncogenes y genes supresores tumorales han sido identificados y han hecho posible el desarrollo de novedosos agentes terapéuticos con un blanco focalizado bien definido, así como la inmunoterapia como opción adicional terapéutica para esta patología. Esta revisión tiene el propósito de proporcionar una guía simple y sencilla sobre lo que llamo la arquitectura tumoral (inmunohistoquímica y análisis molecular) del cáncer de pulmón, en sus tipos con mayor frecuencia.

Palabras clave: cáncer pulmonar; adenocarcinoma; inmunohistoquímica;

${ }^{1}$ Cirugía General y Cirugía del Tórax. Maestría en Administración de Salud. Especialista en Salud Ocupacional. Profesor Asociado Departamento de Cirugía Facultad de Medicina, Universidad Nacional de Colombia. Médico Adscrito Grupo Cirugía de Tórax Fundación Santa Fe de Bogotá. Jefe Cirugía de Tórax Clínica de Marly. Bogotá, Colombia.

\section{Autor de Correspondencia Álvaro Casallas Gómez Correo electrónico: acasallasg@unal.edu.co}

Recibido: 09/06/2021 Aceptado: 10/07/2021 
biología tumoral; genética; biopsias líquidas.

\begin{abstract}
Lung cancer represented the second leading cause of cancer and the leading cause of cancer mortality in the United States by 2020. In 2016, 538,000 lung cancer cases were reported, with 80,775 men and 68,096 women dying in the same year. The five-year survival rate of $15.6 \%$ in 2011 rose to $19.4 \%$ in 2019, probably associated with a decrease in smokers, mainly due to advances in targeted pharmacological therapies and the development of immunotherapies.

Pulmonary adenocarcinoma, particularly in young, nonsmoking women, has shown an increased incidence. However, survival in this population has had significant advances associated with a better, updated understanding of identifiable biological and genetic mechanisms in lung cancer and a better classification of these tumors into types and subtypes.

Numerous advances in immunohistochemical techniques (in the diagnosis and classification of lung cancer and selection of cases for molecular analysis) and the knowledge of genomic alterations associated with various lung cancer types have changed their treatment approach, especially in advanced stages of tumorigenesis. Oncogenes and tumor suppressor genes have been identified, making possible the development of novel therapeutic agents with a well-defined, focused target and immunotherapy as an additional therapeutic option for this pathology.

This review is intended to provide a straightforward guide to the tumor architecture (immunohistochemistry and molecular analysis) of lung cancer in its most common types.
\end{abstract}

Keywords: lung cancer; adenocarcinoma; immunohistochemistry; tumor biology; genetics; liquid biopsies.

\section{Introducción}

El cáncer pulmonar es actualmente un problema de salud pública en diferentes países. Según un reporte de los Estados Unidos en 2020, el cáncer de pulmón fue la segunda causa de todos los cánceres y líder en mortalidad. Se calculó en 2016 un total de 538.243 personas afectadas por esta patología con mortalidad de 80.775 hombres y 68.095 mujeres en el mismo año. El Programa de Evaluación Epidemiológica y Resultados en 2011, reporta sobrevida a cinco años de 15.6 $\%$ y para 2019 de $19.4 \%$, incremento probablemente asociado a disminución de fumadores, a la radioterapia estereotáctica y a avances logrados en terapias farmacológicas focalizadas o dirigidas e inmunoterapia (1).

Es un hecho notorio el incremento del cáncer pulmonar tipo adenocarcinoma, en mujeres jóvenes usualmente no fumadoras. Se ha encontrado en este grupo de población avances significativos en la sobrevida en todos los estadios de la enfermedad, soportado entre otros factores por el conocimiento actual de mecanismos biológicos y genéticos identificables en el cáncer pulmonar, tanto en mujeres como en hombres y en el mejor reconocimiento de tipos y subtipos de tumores. Por otra parte, se debe tener en cuenta que cerca de un $57 \%$ de tumores del pulmón son diagnosticados como lesiones con metástasis extratorácicas, con solo un 16 $\%$ de tumores confinados al sitio primario de origen, lo cual obliga a implementar estrategias que permitan un diagnóstico temprano y tratamiento oportuno (1).

En las últimas décadas se han producido avances significativos en el diagnóstico y clasificación del cáncer del pulmón con el desarrollo y aplicación de técnicas de inmunohistoquímica, las cuales han sido aplicadas a los grupos tumorales principales como el carcinoma escamo celular, el carcinoma de células grandes, el carcinoma neuroendocrino de células grandes y de manera más específica en el grupo del adenocarcinoma con ampliación y caracterización creciente de sus subtipos oncológicos. Las técnicas de inmunohistoquímica también proveen un marco referencial para los tipos de tumores que son susceptibles de análisis molecular. Además, a través de biomarcadores específicos hacen posible excluir tumores de origen metastásico.

El proceso de desarrollo tumoral pulmonar desde la displasia, lesiones pre invasivas o carcinoma in situ hasta el cáncer localizado o metastásico es complejo y está determinado por la acumulación progresiva de oncogenes con ganancia predominante en su función para crecimiento tumoral y a la vez genes supresores de dicho crecimiento, con pérdida recesiva de su función normal de control. Estas son alteraciones genó- 
micas originadas en mutaciones somáticas, deleciones en genes homocigotos, amplificación de genes y translocaciones o en cambios epigenéticos en cromosomas de DNA, que producen desregulación de los cursos celulares normales y su replicación, con lo cual células premalignas se hacen tumorogénicas. Muchos oncogenes y genes supresores tumorales han sido identificados, permitiendo viabilizar el desarrollo de novedosos agentes terapéuticos con un blanco focalizado bien definido. Son complemento al cribado con escanografía de tórax de baja dosis del cáncer pulmonar $(2,3)$.

En esta revisión se expone inicialmente la susceptibilidad genética familiar al cáncer pulmonar y posteriormente se analizan los elementos actuales inmunohistoquímicos aplicados a este tipo de cáncer. Se presenta también, el marco referencial para los tumores que podrían ser susceptibles de análisis molecular y en su biología, profundizar en las alteraciones genéticas y moleculares del cáncer de no pequeñas células y las mutaciones impulsoras de la tumorogénesis, fundamento de las actuales terapias focalizadas y de la inmunoterapia. Se realizan algunas anotaciones sobre el papel actual de los biomarcadores tumorales en decisiones sobre nódulos pulmonares y las tendencias futuras para el diagnóstico del cáncer del pulmón. Se trata de una aproximación sencilla y esquemática a la inmunohistoquímica, y a las evidencias actuales en genética y biología molecular en esta patología, con visión holística, en particular desde la perspectiva de la cirugía del tórax (4).

\section{Susceptibilidad genética familiar al cáncer pul- monar}

La importancia de una historia familiar de cáncer, en especial para personas de familia con inicio temprano de cáncer pulmonar, ha recibido énfasis en varios de los algoritmos de predicción de riesgo diseñados para esta patología. Mucho se ha aprendido acerca de la epidemiología molecular y de marcadores genéticos del huésped para el cáncer pulmonar.

Esta susceptibilidad genética para Ramin Salehi-Rad et al (5) incluye varios tipos de genes: unos de alta penetrancia y baja frecuencia, otros de baja penetrancia y alta frecuencia y factores epigenéticos de polimorfismos adquiridos. Las aproximaciones de los investigadores en la determinación de estas asociaciones familiares, se han dado principalmente en el descubrimiento de genes de alta penetrancia y baja frecuencia.
En efecto, los autores reportan un riesgo dos veces aumentado para cáncer del pulmón en fumadores con historia familiar de cáncer en el pulmón, aunque también el riesgo está presente en no fumadores. No obstante, también se han analizado genes candidatos de susceptibilidad con baja penetrancia y alta frecuencia, entre los cuales se han encontrado más de 1.000 candidatos de susceptibilidad en las pasadas dos décadas. Aunque no hay consenso sobre el efecto susceptible, uno de los estudios reportó 21 de 22 genes incluyendo, entre otros, las denominaciones ATM, CXCR2, CYP1A1, CYP2E1, ERCC1, ERCC2, FGFR4, SOD2, TERT y TP53, todos los cuales parecen presentar asociación significativa con susceptibilidad al cáncer pulmonar (5).

Como conclusión, la susceptibilidad conocida a presentar cáncer pulmonar está determinada al menos en parte por factores genéticos y personas con susceptibilidad genética, podrían entonces tener un riesgo mayor a desarrollar esta patología si son fumadoras de tabaco. Estos determinantes en las personas susceptibles deberán siempre ser objeto de análisis como factor epidemiológico central del cáncer de pulmón (5).

\section{Inmunohistoquímica}

Se han expuesto en la introducción algunos de los nuevos conceptos introducidos con la Clasificación del Cáncer Pulmonar de 2015 de la Organización Mundial de la Salud (OMS) (6), sobre los cuales se realiza una extensión: 1. Ampliación de los requerimientos de la inmunohistoquímica para mejorar la seguridad diagnóstica del cáncer de pulmón, incluyendo los especímenes de resección operatoria. 2. Integración con los análisis moleculares para facilitar estrategias de tratamiento personalizadas en cáncer avanzado de pulmón. 3. Recomendaciones para el diagnóstico y manejo de tejidos en biopsias pequeñas de la lesión y en especímenes de citología. 4. Modificaciones mayores en la aproximación al grupo de adenocarcinoma en especímenes resecados. 5. Restringir el diagnóstico de carcinoma de células grandes a tumores resecados en los cuales no hay una clara morfología o diferenciación inmunhistoquímica o presencia de mucina. 6 . Una nueva definición de los subtipos de carcinoma escamo celular en queratinizante, no queratinizantes y que requieren de coloraciones de inmunohistoquímica, para identificar marcadores de tipo escamo celular. 7. Agrupar los tumores neuroendocrinos aun mante- 
niendo los criterios diagnósticos (6).

Como se mencionó previamente, las técnicas de inmunohistoquímica han permitido la ampliación expuesta y la mejor clasificación del cáncer pulmonar. A continuación se presenta la Clasificación de la OMS de 2015 en su séptima edición, ajustada con base en hallazgos inmunohistoquímicos de preferencia en los grupos principales de tumores pulmonares de no pequeñas células, como son adenocarcinoma, carcinoma escamo celular, tumores neuroendocrinos de células grandes y carcinoma de células grandes. Esta propuesta surge del análisis de especímenes resecados, de material de biopsias y material obtenido en citologías. Las técnicas de inmunohistoquímica también resultan aplicables al carcinoma pulmonar de células pequeñas. La tabla 1 despliega esta clasificación.

Tabla 1. Clasificación de los tumores del pulmón

\section{Tipo histológico y Subtipos}

\section{Tumores Epiteliales}

Adenocarcinoma

Lepidico adenocarcinoma

Acinar adenocarcinoma

Papilar adenocarcinoma

Micropapilar adenocarcinoma

Solido adenocarcinoma

Mucinoso Invasivo adenocarcinoma

Mixto Invasivo Mucinoso y

No mucinoso adenocarcinoma

Colloide adenocarcinoma

Fetal adenocarcinoma

Enterico adenocarcinoma

Mínimamente Invasivo adenocarcinoma

No mucinoso

Mucinoso

Lesiones Preinvasivas

Hiperplasia Adenomatosa Atípica

Adenocarcinoma in situ

No- mucinoso

Mucinoso

Carcinoma Escamocelular

Keratinizante squamous cell carcinomae

No-keratinizante

Basaloide squamous cell carcinomae

Preinvasive lesion

Carcinoma escamocelular in situ

Tumores Neuroendocrinos

Carcinoma células pequeñas

Carcinoma combinado de Células

Pequeñas
Carcinoma Neuroendocrino de Células

Grandes

Carcinoma Combinado

Neuroendocrino de Células Grandes

Tumores Carcinoides

Tumores Típicos

Tumores Atípicos

Preinvasive lesion:

Hiperplasia células Neuroendocrinas

Pulmonares

Difusa Idiopática

Large cell carcinoma

Adenoescamoso carcinoma

Sarcomatoide carcinomas

Pleomorfico carcinoma

Spindle cell carcinoma

Células Gigantes carcinoma

Carcinosarcoma

Blastoma Pulmonar

Otros y no clasificados carcinomas

Lymphoepithelioma-like carcinoma

NUT carcinoma e

Tumores Tipo Glándula Salival

Mucoepidermoide carcinoma

Adenoide quísticocarcinoma

Epithelial-myoepitelial carcinoma

Adenoma Pleomorfico

Papilomas

Papiloma Células Escamosas

Exofítico

Invertido

Glandular papiloma

Papiloma Mixto escamoso y glandular

Adenomas

Pneumocytoma esclerosante e

Alveolar adenoma

Papilar adenoma

Mucinoso cystadenoma

Mucoso glandular adenoma

\section{Tumores mesenquimales}

Hamartoma Pulmonar

Condroma

PEComatous tumores e

Limfangioleomiomatosis s

PEComa, benigno e

Tumor Células Claras

PEComa, maligno

Tumor Miofibroblastico peribronquial

Congénito

Linfangiomatosis Pulmonar Difusa

Tumor Miofibroblástico Inflamatorio

Linfangioendotelioma Epiteliode

Blastoma Pleuropulmonar

Sinovial sarcoma

Sarcoma de la Intima de Arteria 
Pulmonar

Sarcoma pulmonar Mixoide con

EWSR1-CREB1 translocaciones

Tumores Mioepiteliales e

Mioepitelioma

Mioepitelial carcinoma

Tumores Linfohistiocíticos

Linfomas de mucosa asociados a zona

marginal

Extranodal Tejido Linfoide

(Linfoma MALT)

Linfoma difuso de células grandes

Granulomatosis Linfomatoide

Linfoma de Células Grandes B

Intravascular

Histiocitosis de células de Langerhans

Pulmonares

Enfermedad de Erdheim-Chester

Tumores de origen ectópico

Células Germinales tumores

Teratoma, maduro

Teratoma, inmaduro

Intrapulmonar timoma

Melanoma

Meningioma, NOS

\section{Tumores metastásicos}

Fuente: Traducida y adaptada de Travis WD, Brambilla E, Nicholson AG, Yatabe Y, Austin JHM, Beasley MB, et al. WHO Panel. The 2015 World Health Organization Classification of Lung Tumors: Impact of Genetic, Clinical and Radiologic Advances Since the 2004 Classification (7).

Es de anotar que subsiguiente a la clasificación del adenocarcinoma de pulmón en 2011 por IASLC/ ATS/ERS (Asociación Internacional para el estudio del Cáncer de Pulmón/Asociación Americana de Tórax/Sociedad Europea Respiratoria) y con el desarrollo posterior de la clasificación de la OMS en 2015, se decidió clasificar los tumores llamados inicialmente carcinomas de células grandes que tienen expresión de marcadores neumocíticos (T'TF-1 y/o Napsina A), como adenocarcinoma sólido, aún si la producción de mucina está ausente. El adenocarcinoma sólido debe ser distinguido del carcinoma de células escamosas y del carcinoma de células grandes, los cuales rara vez pueden mostrar células con mucina intracelular. El adenocarcinoma sólido debería mostrar al menos dos campos de alto poder al microscopio, con cinco o más células con mucina intracitoplasmática. La Expresión de TTF-1 y/o Napsina A es suficiente, no solo para diagnóstico de adenocarcinoma sólido, sino para separarlo del carcinoma escamo celular $(6,7)$.

Se presentan enseguida las características inmuhohistoquímicas de los principales grupos tumorales del pulmón, en los cuales se centra la mayor parte del trabajo de diferentes laboratorios de patología.

Una de las principales aplicaciones de la inmunohistoquímica en la actualidad, es la separación de adenocarcinomas del carcinoma escamo celular, lo cual cobra mayor relevancia cuando los tumores son pobremente diferenciados. En los tumores del pulmón de células no pequeñas con menos diferenciación y los tumores neuroendocrinos (NET por su sigla en inglés) incluyendo tumores de pequeñas células (SCLC por su sigla en inglés), es usual el requerimiento de un paso adicional de análisis inmunohistoquímico para un diagnóstico de mayor precisión. Estos análisis minimizan la necesidad de bloques tisulares de parafina, requiriendo nuevas opciones de sección micrótomo. Acorta los tiempos de diagnóstico y maximiza la cantidad de tejido conservado para un posible paso siguiente de análisis molecular y genético.

Los marcadores utilizados para diferenciación de adenocarcinoma incluyen TTF-1 (Factor de transcripción tiroidea 1) y Napsina A expresados en más del 85 $\%$ de los adenocarcinomas, los cuales son diagnósticos del tumor y permiten la diferenciación de adenocarcinoma en cáncer de células no pequeñas. En algunos casos, estos marcadores pueden estar presentes en cáncer de pequeñas células SCLC y Carcinomas Neuroendocrinos de Células Grandes $\operatorname{LCNEC}(8,9)$.

Los marcadores expresados en tumores escamo celulares son las citoqueratinas CK5/6, CK5, P63, P40 más específico que P63, desmogleína-3. Se ha considerado que un tumor debe ser clasificado como cáncer escamocelular si cualquiera de estos marcadores es expresado en ausencia de marcadores para adenocarcinoma. Una excepción es el marcador P63 que se encuentra en cerca del $20 \%$ de los adenocarcinomas. Utilizando estas coloraciones alrededor del $90 \%$ de los tumores de células no pequeñas pobremente diferenciados, pueden ser diagnosticados como adenocarcinomas o carcinomas escamocelulares (8).

Un carcinoma pobremente diferenciado que es negativo para todos los anteriores marcadores (inmunofenotipo nulo), puede ser clasificado como de células no pequeñas "NOS" (no especificado de otra ma- 
nera, por su sigla en inglés), en especímenes de biopsia o citología (8).

Otra utilidad de la inmunohistoquímica es la reclasificación de los carcinomas de células grandes, utilizando un panel de inmunohistoquímica. La mayoría de los tumores de células grandes pueden con seguridad ser reclasificados en adenocarcinoma o carcinoma escamo celular.

Los marcadores de citoqueratina son importantes igualmente en el diagnóstico de carcinomas de células pleomórficas y carcinoma de células gigantes. Otros marcadores epiteliales como pancitoqueratina, citoqueratina $\mathrm{AE} / 3, \mathrm{CK} 7$ y EMA (antígeno epitelial de membrana), pueden ser necesarios para confirmar diferenciación epitelial y excluir sarcomas pulmonares.

La inmunohistoquímica sirve para demostrar diferenciación neuroendocrina en tumores con esa morfología. Los marcadores neuroendocrinos utilizados incluyen CD56, sinaptofisina y cromogranina, citoqueratina, CK7, T'TF-1, Napsina A, y P63.

Un panel de inmunohistoquímica para confirmación diagnóstica de cáncer de pequeñas células incluye panqueratina, marcadores neuroendocrinos (CD56, cromogranina y sinaptofisina), TTF-1 (positividad 70$90 \%$ y Ki67 (índice de marcación 70-100 \%).

La inmunohistoquímica también se ha utilizado como plataforma de testeo desplegable rápida y costo efectiva para la práctica en el ámbito de la patología, en la determinación de biomarcadores predictivos a través de anticuerpos dirigidos contra mutaciones específicas en cáncer de pulmón. Por ejemplo, en la búsqueda EGFR (Receptor del Factor de Crecimiento Epidérmico), EML4-ALK (reordenamiento del gen receptor de la tirosina quinasa del linfoma anaplásico) y ROS1 oncogenes C-ros 1.

La inmunohistoquímica es útil en diferenciar metástasis al pulmón, multifocales o solitarias. Se recuerda que algunos cánceres de pulmón pueden presentarse como tumores multifocales. En estos casos, la inmunohistoquímica puede desempeñar un papel fundamental en la separación del cáncer pulmonar de las metástasis, permitiendo acercarse al diagnóstico del tumor primario de origen. Las técnicas de inmunohistoquímica pueden ayudar a confirmar presencia de metástasis e identificar el tejido primario de origen de éstas: los tumores metastásicos muestran un patrón de expresión CK7 y CK20, ausencia de marcadores comúnmente expresados en cáncer pulmonar primario (T'TF-1, Napsina A) y expresión de marcadores órga- no-asociados (9).

La siguiente tabla presenta un resumen de la inmunohistoquímica de acuerdo con el tipo de tumor pulmonar (Tabla 2).

\section{Lesiones preinvasiva}

La clasificación de las lesiones preinvasivas para cáncer pulmonar ha tenido cambios mayores a partir de la Clasificación de la OMS de 1967, en la cual no se hacía referencia a lesiones de este tipo. Actualmente y en su clasificación de 2015, se reconocen tres categorías de lesiones preinvasivas:

- Categoría 1. Para Carcinoma Escamo Celular: Displasia Escamosa Bronquial y Carcinoma In Situ.

- Categoría 2. Para Adenocarcinoma: Hiperplasia Adenomatosa Atípica (AAH) y Adenocarcinoma In Situ (AIS).

- Categoría 3. Para tumores Carcinoides: Hiperplasia de Células Neuroendocrinas Pulmonares Difusa Idiopática (DIPNECH).

En la definición de estas categorías la inmunohistoquímica y el análisis molecular amplían su alcance clasificatorio (4).

\section{Evaluación o testeo molecular genómico del cáncer pulmonar}

En la clasificación del cáncer pulmonar de células no pequeñas se ha alcanzado un gran avance mediante marcadores moleculares, los cuales se utilizan para identificar terapias focalizadas. El reconocimiento de la diversidad biológica del cáncer pulmonar ha impactado el tratamiento y el pronóstico, lo cual guarda estrecha relación con la información derivada de los biomarcadores moleculares genéticos.

El cáncer de pulmón está más frecuentemente asociado al tabaquismo y se comporta como un grupo heterogéneo de patologías con un número significativo de alteraciones genéticas y epigenéticas. Los anteriores cambios pueden inducir la aparición de vías de oncogenicidad o provocar la inhibición de genes supresores que impiden el desarrollo de tumores, factores que son críticos para la transformación maligna de células precursoras tumorales. A estos mecanismos se adiciona el papel de las características del microambiente en el cual se desarrolla un tumor y los factores del huésped, en su capacidad para instaurar una respuesta inmune a 
Tabla 2. Patrones de Coloración de Inmunohistoquímica según características por tipo de tumor

\begin{tabular}{|c|c|c|c|c|c|c|c|}
\hline Tipo de Tumor & $\begin{array}{c}\text { TTF- } \\
1\end{array}$ & Napsina A & $\begin{array}{c}\text { Citoqueratinas } \\
5 / 6\end{array}$ & $\mathrm{p} 40$ & CD56 & Sinaptofisina & Cromogranina \\
\hline Adenocarcinoma & + & + & - & - & - & - & - \\
\hline $\begin{array}{l}\text { Carcinoma } \\
\text { Escamo Celular }\end{array}$ & - & - & + & + & - & - & $-p 63$ \\
\hline $\begin{array}{l}\text { Carcinoma de } \\
\text { células pequeñas }\end{array}$ & + & - & - & - & + & + & + \\
\hline $\begin{array}{l}\text { Carcinoma de } \\
\text { células grandes }\end{array}$ & - & - & - & - & - & - & - \\
\hline
\end{tabular}

Fuente: Traducida y adaptada de Konopka KE. Diagnostic Pathology of Lung Cancer (10).

cada paso de la tumorogénesis.

El conocimiento del espectro genómico del cáncer pulmonar y de la biología del microambiente, además de la respuesta inmune del huésped, han permitido el desarrollo de novedosas terapias focalizadas e inmunoterapias, cuya utilización en esquemas de primera o segunda línea, han sido efectivas en términos de respuesta y de sobrevida comparadas con la quimioterapia general utilizada décadas atrás.

Enseguida se presentan las alteraciones genéticas y moleculares de mayor frecuencia en el cáncer pulmonar.

Varias alteraciones genéticas han sido identificadas como promotoras e impulsadoras de la tumorogénesis en el cáncer pulmonar de células no pequeñas. Entre las más importantes cascadas identificadas están ERK- MAPK (Extracelular Signal regulated Kinase - mitogen activated protein kinase). En esta cascada, mutaciones activadas en EGFR, RAS y BRAF halladas en cáncer de pulmón, llevan a transformación maligna y a cambios en la expresión de estos genes. Pacientes con tumores KRAS (Kristen Rat Sarcoma) mutantes, presentes en el $25 \%$ de adenocarcinomas, tienen por su presencia, falla terapéutica con inhibidores de tirosina - kinasa (TKIs) y mal pronóstico con pobre sobrevida global (11).

\section{Mutaciones del Receptor Factor de Crecimiento Epidémico (EFGR)}

El receptor de superficie epidérmico EFGR se dimeriza y activa las tyrosin kinasas. Esta modificación contribuye al control normal de la proliferación celular angiogénesis, adherencia, motilidad y apoptosis. Cuando este control se pierde, contribuye al potencial de malignidad de una célula de cáncer pulmonar. Las Mutaciones en EFGR se presentan en el $15 \%$ de los adenocarcinomas de pulmón en los Estados Unidos. La forma más común se presenta en el exon 19 y en el exon 21 (L858R); tienen una ligera mayor probabilidad de manifestarse en mujeres y en no fumadores.

\section{Traslocaciones en EML4 - ALK (Echinoderm Microtubule-Associated Protein-Like 4 (EML4 - Anaplasic Linfoma Kinasa ALK)}

La modificación por traslocaciones de ALK y en EML4 a partir de una inversión en el brazo corto del cromosoma 2, resulta en una proteína de fusión EML4-ALK, activando varias vías conductoras de proliferación y sobrevida celular. Estas traslocaciones están presentes en $3 \%$ a $5 \%$ de pacientes con cáncer de células no pequeñas, particularmente adenocarcinomas.

Reordenamientos ROS 1 (Rective Oxigen Species ROS). ROS1 es un receptor de tirosina kinasa de la familia de receptores de insulina. Alrededor de 12 diferentes proteínas similares forman fusiones con ROS1, generando actividad constitutiva de kinasa y así conducen a transformación celular. Los rearreglos o reordenamintos de ROS 1 son encontrados en $1 \%$ a $2 \%$ de especímenes de tumores de células no pequeñas y son más frecuentes en pacientes sin o con ligera historia de tabaquismo y con tumores del tipo adenocarcinoma.

Mutaciones BRAF V600 (Mutations in V-raf murine sarcoma viral oncogene homolog $B$ BRAF). Es otra vía de proteína kinasa RAS. Las mu- 
taciones BRAF se identifican en $2 \%$ a $7 \%$ de tumores adenocarcinomas de pulmón y $4 \%$ de carcinomas escamocelulares; constituyen otra vía de la proteína-kinasa y son un foco principal para terapias inhibitorias. Su mutación más común es V600. En estudios, 20 pacientes con mutación V600 tratados con vemurafenib, mostraron una rata de respuesta evaluable del $42 \%$ y una sobrevida libre de progresión media de 7.3 meses; otros 17 pacientes recibieron dabrafenib y demostraron una respuesta global del $54 \%$. En un estudio retrospectivo de casos con mutaciones BRAF V600 tratados con varios inhibidores de BRAF, se encontró una rata de respuesta similar de $53 \%$ y sobrevida libre de progresión media de cinco meses (8).

\section{Reordenamientos o fusions RET (Rearrangements)}

Los reordenamientos o fusiones de RET, un protooncogene que codifica una tirosina kinasa involucrada en emisión de señales extracelulares, se identifican en $2 \%$ de los carcinomas de células no pequeñas del pulmón, primariamente adenocarcinomas en individuos no fumadores. Un total de 30 pacientes con adenocarcinomas exhibiendo reordenamientos RET fueron tratados con el cabozantinib. Se obtuvo una rata de respuesta global de $28 \%$ y enfermedad estable de $72 \%$, con sobrevida libre de progresión media de 7 meses (8).

\section{HER2 Mutaciones (Receptor de Factor de Crecimiento Humano Epidérmico)}

Las mutaciones HER2 son mutaciones conductoras u orientadoras que se presentan en $2 \%$ de los carcinomas de pulmón de células no pequeñas, primariamente en mujeres, nunca fumadoras y de manera casi exclusiva con histología de adenocarcinoma. Inserciones en el exon 20 llevan a la activación del receptor HER2, generando una cascada descendente de vías emisoras de señales, las cuales orientan transformaciones neoplásicas (5).

\section{MET (Factor de Transición Epitelial Mesen- quimatoso) - Protooncogene}

El MEN es un gen receptor de transmembrana de tirosina kinasa que se puede alterar por sobreexpresión o por amplificación; su presencia es indicativa de mal pronóstico. La Amplificación de MET es también un mecanismo identificado de resistencia adquirida para EFGR (8).

\section{Testeo recomendado}

Basados en la anterior información, The National Comprehensive Cancer Network Guidelines para cáncer de células no pequeñas (NSCLC) en 2016 recomendó que todos los pacientes con cáncer metastásico con histología de subtipos adenocarcinoma, carcinoma de células grandes y NSCLC no especificados de otra manera, fueran testeados para mutaciones EFGR y reordenamientos ALK. Los pacientes con carcinoma escamocelular también pueden ser considerados para los tests, especialmente si se presentan en individuos nunca fumadores, con histología mixta o especímenes de tipo biopsia. Hasta el presente no existe información que soporte el testeo de pacientes tratado con intención curativa. No obstante, The American College of Pathologist recomienda pruebas rutinarias para todos los pacientes, incluidos aquellos con NSCLC resecables.

Otros biomarcadores en evaluación activa incluyen el receptor del factor de crecimiento epidérmico 2, el receptor del factor de crecimiento de fibroblastos 1 (FGFR1), el receptor del dominio discoide tirosina kinasa 2, (DDR2), homólogo de fosfatasa y tensina, MAP2K proteína activada mitogena kinasa y fosfatidil inositol 3 kinasa $(8,12,13)$.

Para el testeo o caracterización molecular del NSCLC, el primer tipo a identificar es el adenocarcinoma y su diferenciación del carcinoma escamo celular.

Para esta caracterización se han desarrollado múltiples paneles, con la idea de buscar las opciones terapéuticas focalizadas. Las alteraciones moleculares básicas incluidas en los paneles son las mutaciones EFGR y los reordenamientos ALK. No obstante, los paneles para tamizaje incluyen otros elementos distintos como son mutaciones KRAS, reordenamientos ROS1, reordenamientos RET, mutaciones BRAF, mutaciones ERBB2/HER2 y mutaciones MET.

Los oncogenes más frecuentemente mutados en adenocarcinoma son el KRAS (Kristen rat sarcoma) y el EGFR (receptor del factor de crecimiento epidémico), implicados en la iniciación de la tumorogénesis. Aunque estas mutaciones son por sí mismas exclusivas, cuando las dos coexisten, la mutación KRAS conduce a propiciar resistencia a los inhibidores de EFGR. Otros oncogenes blanco u objetivo en adenocarcinoma incluyen el HER2 (receptor 2 del factor de crecimiento epidérmico humano), el protooncogene MET y el protooncogene RET. Como se refirió 
previamente, los oncogenes fusionados involucrando ALK (linfoma kinasa anaplásica) y especies de protooncogenes 1 reactivos al oxígeno, también se han validado en el diagnóstico molecular del adenocarcinoma. Es de anotar que esto contrasta con la no prevalencia de mutaciones funcionales conductoras en el carcinoma escamocelular (5).

Por otra parte, Salehi-Rad et al también refieren que las mutaciones de mayor frecuencia en los genes supresores del crecimiento tumoral en adenocarcinoma incluyen la proteína $\mathrm{p} 53 \mathrm{a}$, la proteína 1 asociada a kelch - like tipo ECH, la kinasa hepática B1 LKB1 y neurofibromina 1 NF1. La mutación p53 que es sensor de daño genómico y supresor de proliferación, está implicado en la progresión del crecimiento de los tumores y está presente en $90 \%$ de los carcinomas escamocelulares. A su vez, el inhibidor 2 a dependiente de kinasa -ciclina; CDKN2A un supresor que regula el ciclo celular también está inactivado en $70 \%$ de los tumores tipo escamocelular (5).

Igualmente, Salehi-Rad et al hacen diferenciación del espectro genómico entre fumadores y no fumadores. Los tumores de células no pequeñas en fumadores tienen las mayores cargas mutacionales de todos los tumores malignos y con frecuencia, la transición de exposición al tabaco de citosina a adenina. En contraste, los tumores de células no pequeñas del pulmón en individuos que nunca han fumado tienen un número diez veces más bajo de puntos de mutación, comparado con fumadores y contienen con mayor frecuencia la transición de citosina a tiamina. Adicionalmente, la prevalencia de oncogenes dependientes de NSCLCs con mutaciones EFGR y/o ALK y traslocaciones ROS1, es más alta en nunca fumadores, mientras KRAS y TP53 es más común en fumadores (5).

\section{Técnicas específicas para la evaluación genética y molecular}

Para tamizaje de mutaciones de punto se han utilizado modalidades de testeo focalizado, como secuenciación de DNA y reacción en cadena de polimerasa (PCR). En el caso de reordenamientos de genes se pueden analizar igualmente mediante secuenciación; sin embargo, para testeo focalizado la hibridización fluorescente in situ (FISH) actualmente se considera el estándar para estudio molecular de los reordenamientos de ALK.

La PCR en tiempo real, el FISH y la secuenciación directa de DNA, son métodos de uso común para detección de la fusión de genes EML4-ALK (8).

Para el análisis de información molecular y genéti$\mathrm{ca}$, se ha desarrollado recientemente lo que se conoce como Secuenciación de Próxima Generación (SNG por su sigla en inglés), también conocida como Highthroughput sequencing, que permite analizar tanto DNA como RNA en una plataforma única (8).

La Secuenciación de Próxima Generación también se puede utilizar para analizar células tumorales circulantes (CTCs) depositadas en el torrente sanguíneo a partir del tumor, como también material genético liberado por las células tumorales a la circulación como DNA tumoral libre circulante (ctDNA). Estos análisis conocidos como "biopsias líquidas" que utilizan sangre periférica o suero, proporcionan una opción o alternativa para el análisis directo de tumores sólidos. El perfil genético alcanzado con CTCs y ctDNA puede ser usado como parámetro sustituto para detectar mutaciones, para evaluación de límites tumorales, monitoreo de respuesta al tratamiento y detección de resistencia al tratamiento basada en mutaciones (8).

\section{El rol del microambiente tumoral y del sistema inmune del huésped}

Todos los anteriores eventos genéticos y moleculares no ocurren por sí solos de manera independiente. La capacidad para la carcinogénesis se asocia a dos factores adicionales: uno, la reprogramación por las células premalignas o tumorales de la composición del microambiente tumoral TME, el cual permite su desarrollo y replicación. Un segundo elemento está constituido por el sistema inmune del huésped y que se constituye en un componente crítico en la medida en que las células inmunes están presentes dentro del microambiente tumoral, en el cual o bien pueden tener un papel significativo en la erradicación del tumor o, por el contrario, promueven un microambiente inmunosuprimido a través de una variedad significativa de moléculas inmunosupresoras. Entre estas se encuentran: factor transformante del crecimiento beta TGF- $B$, interleuquina 6 IL-6, prostaglandina E2 PGE2, factor de crecimiento del endotelio vascular (VEGF) y una variedad significativa de acumulación de células inmunosupresoras regulatorias como linfocitos T reguladores Treg y células supresoras derivadas de tejido mieloide (MDSC), que favorecen la progresión de la lesión maligna (5). 
En la detección temprana del cáncer pulmonar Salehi-Rad et al hacen referencia a un estudio realizado, utilizando secuenciación profunda focalizada de DNA y RNA en adenocarcinomas y también en lesiones adyacentes precursoras de adenocarcinoma, como hiperplasia adenomatosa atípica (AAH) en el cual se reveló la presencia de mutaciones de carcinogenicidad tales como BRAF y KRAS, localizadas en la lesión premaligna AAH (5).

Otro aspecto de interés tiene relación con el manejo de la enfermedad metastásica en cáncer pulmonar de células no pequeñas, independiente de los avances logrados con los inhibidores de tirosina kinasa y en la tipificación genética y molecular de los tumores primarios del pulmón presentada previamente. En este caso, la inmunoterapia podría ser una estrategia plausible de tratamiento. Las estrategias de mayor éxito utilizan los anticuerpos para bloquear receptores inhibitorios o puntos de control inmunitario (checkpoints en inglés). Dos de éstas moléculas incluyen las programadas para muerte celular PD1 y la Proteína-4 citotóxica asociada a linfocitos T. La primera, PD1, ha demostrado respuestas superiores y duraderas, comparada con la quimioterapia tradicional, cuando se utiliza como primera línea en individuos con más de $50 \%$ de expresión de proteína PD1 y su unión como proteína ligadora (PDL-1) en coloraciones de inmunhistoquímica. Este complejo no permite que las células T destruyan las células que contienen PDL-1, en este caso, las células cancerosas. Los anticuerpos de control inmunitario se pueden adherir a PDL-1 e impiden que esta proteína se una a PD1, libera el sistema inmunitario y permite que las células $T$ destruyan las células tumorales. Combinaciones de PDL-1 y Proteína-4 anticitotóxica asociada a linfocitos $\mathrm{T}$ y quimioterapia continúan en evaluación (14).

\section{Biología molecular - biomarcadores en el manejo de nódulos pulmonares}

La utilización de la escanografía de tórax tanto en la indicación de tamizaje como en el diagnóstico del cáncer pulmonar, ha permitido la identificación cada vez más frecuente de nódulos pulmonares. La caracterización de los nódulos pulmonares a través de las imágenes permite su clasificación en nódulos de bajo riesgo para cáncer pulmonar, otros con alto riesgo y entre los dos grupos anteriores los nódulos indeterminados con riesgo intermedio. El cálculo de riesgo de malignidad en los nódulos presentes en el pulmón mediante diversos métodos de cálculo y estimación médica permite una estratificación del riesgo en muy bajo (<=10\%), riesgo intermedio $(11 \%-64 \%)$ y alto riesgo $(>65 \%)$. Es importante recordar que los nódulos subsólidos en las imágenes tienen un riesgo alto de malignidad, en comparación con los nódulos sólidos y por tanto, el seguimiento a nódulos mediante imágenes pretende identificar el crecimiento o desarrollo en el mismo de un componente sólido dentro de su estructura, momento en el cual el tratamiento debe ser la resección quirúrgica.

Resulta evidente que la diferenciación de un nódulo benigno de otro maligno en el presente depende en esencia de sus características tomográficas en cuanto a su composición o estructura, su forma, sus bordes, presencia de espiculaciones, ausencia de calcio. Sin embargo, en un nódulo sólido sin características de benignidad, entre 8 y $30 \mathrm{~mm}$ de diámetro mayor, la identificación de un biomarcador que haga la diferencia entre benigno y maligno, con seguridad sería muy útil (15).

Varios protocolos han definido que para los nódulos pulmonares con riesgo bajo, el seguimiento se debería realizar mediante imágenes tomográficas, mientras los nódulos con riesgo alto, el tratamiento es la extirpación quirúrgica o la radioterapia estereotáctica, acorde con la condición del paciente. Al mismo tiempo, se discute que para los nódulos con riesgo intermedio, varias formas de diagnóstico y seguimiento incluyen, entre otros, tomografía de emisión de positrones PET/escanografía de tórax con sensibilidad cercana a $90 \%$ pero con baja especificidad (61\%- $77 \%$ ), biopsia percutánea o broncoscópica, procedimientos con morbilidad bien conocida por neumólogos y cirujanos (15).

Consideraciones teóricas permiten inferir que un biomarcador potencial podría identificar un nódulo con alta o baja probabilidad de malignidad, de manera que lo incluya en el grupo de alta probabilidad de malignidad o lo excluya del grupo de baja probabilidad de ser maligno. Lo anterior ayudaría a decidir el mejor tratamiento para cada caso. Un beneficio adicional de un biomarcador de este tipo estaría en evitar demoras diagnósticas, al tiempo que se reducen las complicaciones de procedimientos invasivos percutáneos o broncoscópicos. Los biomarcadores, no obstante, también tendrían limitaciones en la caracterización de 
benignidad o malignidad, como un falso negativo con demora en el diagnóstico y tratamiento de un nódulo maligno con incremento en mortalidad. Es necesario definir mediante estudios clínicos la utilidad clínica de un potencial para el manejo de nódulos pulmonares del pulmón, en particular aquéllos con riesgo intermedio de malignidad $(15,16,17)$.

\section{Tendencias futuras en el diagnóstico del cáncer de pulmón}

La broncoscopia es frecuentemente no diagnóstica en lesiones sospechosas de malignidad, lo cual resulta en la necesidad de realizar otros procedimientos, algunos invasivos, para obtener un diagnóstico definitivo. En dos estudios prospectivos multicéntricos AEGIS1 y AEGIS2, se hizo medición de una expresión genética clasificatoria en células epiteliales obtenidas de los bronquios fuente con apariencia normal, para evaluar la probabilidad de cáncer pulmonar. En AEGIS 1 se incluyeron 298 casos y en AEGIS 2, 341 pacientes. Un $43 \%$ de broncoscopias realizadas no fueron diagnósticas de carcinoma. En AEGIS 1 el clasificador caracterizó el área bajo la curva definida con valor de 0.78 (95\% intervalo de confianza), sensibilidad del $88 \%$ y especificidad de $47 \%$. En AEGIS 2 el clasificador produjo un área bajo la curva con un valor de 0.74 , sensibilidad $89 \%$ y especificidad $47 \%$. La combinación del resultado del clasificador combinado con la broncoscopia tuvo sensibilidad de $96 \%$ en AEGIS 1 y de $98 \%$ en AEGIS 2. Independiente de un pretest intermedio de probabilidad de cáncer, el valor predictivo negativo fue de $91 \%$ entre los pacientes con un examen no diagnóstico broncoscópico.

Se concluyó que un sistema clasificatorio de la expresión genética celular mejora el resultado positivo de la broncoscopia en detección de cáncer de pulmón. En pacientes con riesgo intermedio para malignidad con broncoscopia negativa y un puntaje del clasificador negativo, se avala un abordaje más conservador (18).

Un segundo elemento clasificatorio ha sido propuesto por Silvestri et al; los autores lo presentan como Clasificador Proteómico Plasmático en Nódulos Pulmonares. En su estudio evaluaron el clasificador en la identificación de nódulos pulmonares benignos, en pacientes con probabilidad de cáncer pulmonar del $50 \%$. Incluyeron pacientes con nódulos entre 8- $30 \mathrm{~mm}$ y mediante espectrofotometría de masa, se midió la cantidad de las proteínas plasmáticas LG3BP y C163A. Los resultados fueron incorporados y analizados mediante un modelo de predicción de riesgo clínico para identificar el carácter benigno de las lesiones. Concluyeron en su trabajo que cuando se utiliza la evaluación en pacientes con probabilidad de cáncer del $50 \%$, el clasificador proteómico integrado identifica nódulos pulmonares benignos con buenas características para interpretación. Este sistema utilizado en la práctica clínica, podría reducir el espectro de procedimientos diagnósticos en la evaluación de los nódulos benignos del pulmón (19).

Un editorial de Nawar Al Nasrallah, et al [17] hace algunas consideraciones sobre el sistema clasificatorio proteómico y al final, definen que el estudio representa un paso hacia adelante en el desarrollo de un perfil molecular que ayudará en la clasificación de nódulos pulmonares con riesgo intermedio para malignidad, limitando los procedimientos innecesarios con impacto sobre los pacientes y sobre los costos hospitalarios.

De otra parte, el uso de la radiómica también se enfoca como tendencia hacia el futuro. Consiste en la utilización de bases de datos que contienen gran número de imágenes médicas combinadas con aprendizaje por computador, con el objeto de encontrar rasgos cualitativos y cuantitativos en las imágenes, las cuales guardan relación con estados de enfermedad. En cáncer pulmonar se pueden desarrollar biomarcadores radiómicos a partir de imágenes de tomografías axiales computadorizadas o de PET. Combinaciones de estos marcadores radiómicos con las características clínicas del paciente y con análisis moleculares, pueden contribuir a mejorar la seguridad diagnóstica y el pronóstico, en especial en la evaluación de los nódulos pulmonares (15).

\section{Puntos clave}

Existe susceptibilidad genética y familiar al cáncer pulmonar.

La inmunohistoquímica es una herramienta valiosa en la clasificación de tipos y subtipos de cáncer del pulmón.

La inmunohistoquímica puede ser utilizada en al diagnóstico temprano del cáncer pulmonar.

La inmunohistoquímica facilita la orientación de pacientes que requieren estudios de patrones genéticos y moleculares en cáncer pulmonar, en particular para subtipos mal diferenciados histológicamente. 
El análisis de los patrones genéticos y moleculares en cáncer pulmonar, permite actualmente elegir terapias focalizadas efectivas.

Con las llamadas "biopsias líquidas" es posible la caracterización molecular de células tumorales liberadas a la sangre por el tumor o de su DNA circulante.

En nódulos pulmonares con baja probabilidad de malignidad, la conducta puede ser expectante o de seguimiento periódico por imágenes.

En nódulos pulmonares con alto riesgo de malignidad, la conducta es la extirpación operatoria o la radioterapia focalizada.

En nódulos pulmonares con probabilidad intermedia de malignidad o indeterminados, la inmunohistoquímica y los análisis genéticos y moleculares han alcanzado algunos desarrollos para el diagnóstico y diferenciación entre benignos y malignos, información que requiere ser consolidada en el futuro.

El microambiente tumoral y los patrones de respuesta inmune del paciente en correlación con la susceptibilidad genética, son esenciales para el desarrollo del cáncer pulmonar.

El Sistema Clasificatorio de la expresión genética celular, mejora los resultados de la broncoscopia en detección de cáncer de pulmón.

En pacientes con riesgos intermedios para malignidad con broncoscopia negativa, un puntaje del clasificador negativo soporta una conducta conservadora expectante.

El Clasificador Proteómico Integrado es útil en la identificación de nódulos pulmonares benignos, en individuos con pretest con probabilidad de cáncer pulmonar del $50 \%$.

En lesiones pre invasivas de cáncer pulmonar hay algún beneficio de la aplicación de pruebas de inmunohistoquímica y de análisis genéticos y moleculares para su caracterización.

\section{Paneles de inmunohistoquímica y de análisis genómico y molecular disponibles en Colombia}

\section{Sistema de paneles para análisis inmunohistoquímico}

El análisis inmunohistoquímico puede ser efectuado en forma manual o automatizada.

Los sistemas para análisis inmunohistoquímico utilizan anticuerpos monoclonales; contienen 150 o más opciones de identificación de patrones inmunohistoquímicos. El uso de otro sistema paralelo con igual objetivo, permite a un laboratorio analizar hasta 300 patrones focalizados de acuerdo al tipo de lesión tumoral en evaluación. La selección del tipo de pruebas a realizar relacionado con el tipo de tumor y el análisis e interpretación de los resultados, corresponde a patólogos especializados en un laboratorio de alto nivel.

\section{Sistema de paneles para análisis genómico y molecular}

Al igual que la inmunohistoquímica, los estudios de genética y análisis molecular se realizan en sistemas automatizados a cargo de patólogos especializados en su análisis e interpretación. Estos sistemas utilizan fundamentalmente técnicas de secuenciación de DNA y RNA y se analizan de acuerdo al tipo de tumor en estudio.

\section{Referencias}

1. Bade BC, De la Cruz CS. Lung Cancer 2020: Epidemiology, Etiology, and Prevention. Clin Chest Med. 2020 Mar;41(1):1-24. doi:10.1016/j. ccm.2019.10.001

2. Mazzone PJ, Silvestri GA, Patel S, Kanne JP, Kinsinger LS, Wiener RS, et al. Screening for lung cancer: CHEST guideline and expert panel report. Chest. 2018 Apr;153(4):954-985. doi: 10.1016/j.chest.2018.01.016.

3. Thomas NA, Tanner NT. Lung Cancer Screening: Patient Selection and Implementation. Clin Chest Med. 2020 Mar;41(1):87-97. doi: 10.1016/j. ccm.2019.10.006

4. Casallas AG. Datos en archivo. Febrero 28 de 2017.

5. Salehi-Rad R, Li R, Paul MK, Dubinett SM, Liu B. The Biology of Lung Cancer: Development of More Effective Methods for Prevention, Diagnosis, and Treatment. Clin Chest Med. 2020 Mar;41(1):25-38. doi: 10.1016/j.ccm.2019.10.003

6. Travis WD. Lung Cancer Pathology: Current Concepts. Clin Chest Med. 2020 Mar;41(1):6785. doi: 10.1016/j.ccm.2019.11.001.

7. Travis WD, Brambilla E, Nicholson AG, Yatabe Y, Austin JHM, Beasley MB, et al. WHO Panel. The 2015 World Health Organization Classification of Lung Tumors: Impact of Genetic, Clinical and Radiologic Advances Since the 2004 Classification. J Thorac Oncol. 2015 Sep;10(9):12431260. doi: $10.1097 / J T O .0000000000000630$. 
8. Zheng M. Classification and Pathology of Lung Cancer. Surg Oncol Clin N Am. 2016 Jul;25(3):447-68. doi: 10.1016/j.soc.2016.02.003.

9. Uchida A, Samukawa T, Kumamoto T, Ohshige M, Hatanaka K, Nakamura Y, et al. Napsin A levels in epithelial lining fluid as a diagnostic biomarker of primary lung adenocarcinoma. BMC Pulm Med. 2017 Dec 12;17(1):195. doi: 10.1186/ s12890-017-0534-z.

10. Konopka KE. Diagnostic Pathology of Lung Cancer. Semin Respir Crit Care Med. 2016 Oct;37(5):681-688. doi: 10.1055/s-00361592172.

11. Naylor EC, Desani JK, Chung PK. Targeted Therapy and Immunotherapy for Lung Cancer. Surg Oncol Clin N Am. 2016 Jul;25(3):601-9. doi: 10.1016/j.soc.2016.02.011.

12. Mazzone PJ, Sears CR, Arenberg DA, Gaga M, Gould MK, Massion PP. Evaluating molecular biomarkers for the early detection of lung cancer: when is a biomarker ready for clinical use? An official American Thoracic Society Policy Statement. Respir Crit Care Med. 2017 Oct 1;196(7):e15-e29. doi: 10.1164/rccm.

13. Travis WD, Brambilla E, Noguchi M, Nicholson AG, Geisinger KR, Yatabe Y, et al. International association for the study of lung cancer/ american thoracic society/european respiratory society international multidisciplinary classification of lung adenocarcinoma. J Thorac Oncol. 2011 Feb;6(2):244-85. doi: 10.1097/JTO. ob013e318206a221.
14. Moon EK, Langer CJ, Albelda SM. The Era of Checkpoint Blockade in Lung Cancer: Taking the Brakes Off the Immune System. Ann Am Thorac Soc. 2017 Aug;14(8):1248-1260. doi: 10.1513/ AnnalsATS.201702-152FR.

15. Sears CR, Mazzone PJ. Biomarkers in Lung Cancer. Clin Chest Med. 2020 Mar;41(1):115-127. doi: 10.1016/j.ccm.2019.10.004.

16. Wortzel I, Seger R. The ERK Cascade: Distinct Functions within Various Subcellular Organelles. Genes Cancer. 2011 Mar;2(3):195-209. doi: 10.1177/1947601911407328.

17. Al Nasrallah N, Sears CR. Biomarkers in Pulmonary Nodule Diagnosis: Is It Time to Put Away the Biopsy Needle? Chest. 2018 Sep;154(3):467468. doi: 10.1016/j.chest.2018.04.032.

18. Silvestri GA, Vachani A, Whitney D, Elashoff M, Porta Smith K, Ferguson JS, et al. A Bronchial Genomic Classifier for the Diagnostic Evaluation of Lung Cancer. N Engl J Med. 2015 Jul 16;373(3):243-51. doi: 10.1056/NEJMoa1504601.

19. Silvestri GA, Tanner NT, Kearney P, Vachani A, Massion PP, Porter A, et al. PANOPTIC Trial Team. Assessment of Plasma Proteomics Biomarker's Ability to Distinguish Benign from Malignant Lung Nodules: Results of the PANOPTIC (Pulmonary Nodule Plasma Proteomic Classifier) Trial. Chest. 2018 Sep;154(3):491-500. doi: 10.1016/j.chest.2018.02.012. 